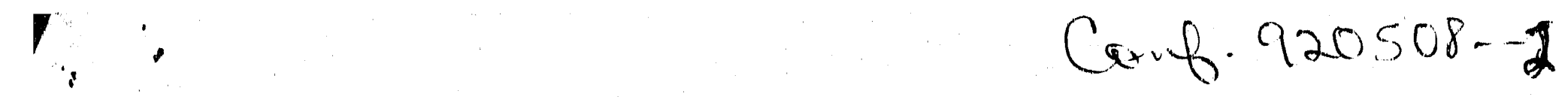

ANL NU-74983

DE92 0161.91

\title{
Fungal Degradation of Organophosphorous Insecticides
}

*John A. Bumpus, ${ }^{1}$ Satya N. Kakar, ${ }^{2}$ and R.D. Coleman²

${ }^{1}$ Center for Bioengineering and Pollution Control and the

Department of Chernistry and Biochemistry

University of Note Dame

Notre Dame, Indiana 46556

2Argonne National Laboratory

Environmental Research Division

9700 South Cass Avenue

Argonne, Illinois $60439-4833$

*Address of the Correspondirı Author: J.A. Bumpus, Department of Chemistry and

Biochemistry, University of Notre Dame, Notre Dame, Indiana 46556

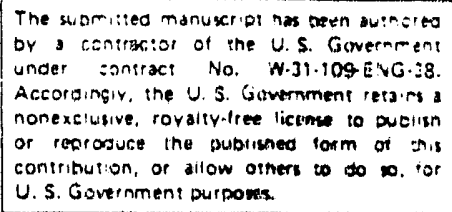

Work supported by the U.S. Deparment of Energy under CRADA Agreement C9100300/01 with the University of Notre Dame. 


\section{DISCLAIMER}

This report was prepared as an acceent of work sponsored by an agency of the United States Government. Neither the United State: Government nor any agency thereof, nor any of their employees, makes any warranty, express ur implied, or assumes any legal liability or responsibility for the accuracy, completeness, or usefulness of any information, apparatus, product, or process disclosed, or represents that its use would not infringe privately owned rights. Reference herein to any spocific commercial product, process, or service by trade name, trademark, manufacturer, or otherwise does not necessarily constitute or imply its endorsement, recommendation, or favoring by the United States Government or any agency thereof. The views and opinions of authors expressed herein do not necessarily state or reflect those of the United States Government or any agency therenf. 


\section{Summary}

Organophosphorous insecticides are used extensively to treat a variety of pests and insects. Although as a group they are easily degraded by bacteria in the environment, a number of them have half-lives of several months. Little is known about their biodegradation by fungi. We have shown that Phanerochaete chrysosporium can substantially degrade chlorpyrifos, fonofos, and terbufos $(27.5 \%, 12.2 \%$, and $26.6 \%$, respectively) during 18-day incubation in nitrogen-limited stationary cultures. The results demonstrate that the chlorinated pyridinyl ring of chlorpyrifos and the phenyl ring of fonofos undergo ring cleavage during biodegradation by the fungus. The usefulness of the fungus system for bioremediation is discussed.

\section{Introduction}

Organophosphorus insecticides are used extensively in agriculture to treat a variety of soil pests including corn rootworms, cut worms, and wire worms and to control orchard pests such as the apple flea weevil, the plum curculio. and the coddling moth $(1,2)$. Many of these compounds are effective as topical sprays and are used to control housenold pests and aerial insects on field crops and ornamental plants $(1,2)$. Some organophosphorus insecticides are used in veterinary medicine to control ticks and fleas $(1,2)$.

Many organophosphorous insecticides appear to function as cholinesterase inhibitors $(1,2)$. They are typically quite lethal to insects but are often relatively innocuous to fish, mammals, and birds. Compared to certain effective insecticides (DDT, chlordane, and dieldrin, for example), they are not very persistent in the environment. Some organophosphorous insecticides are, however, moderately persistent and have half-lives of several months in soil $(2-4)$. Furthernore, substantial amounts of relatively stable and biologically active metabolites may 
persist in soils either as free metabolite or tighty bound to soil $(3,4)$. Mineralization by soil microorganisms appears to be a significant mode of organophosphorous insecticide removal $(3,4)$.

The wood-rotting fungus Phanerochaete chrysosporium can degrade a wide variety of structurally diverse or fanopollutants to carbon dioxide (5-10). Because of its unique biodegradative abilities, considerable interest exists in its role and that of other lignin-degrading fungi in the degradation of agricultural chemicals and their metabolites. In the present investigation, we have shown that $P$. chrysosporium can mediate extensive degradation of three representative organophosphorous insecticides.

\section{Methods}

Fungus. Phanerochaete chrysosporium BKM-F-1767 was obtained from the U.S. Deparment of Agriculture Forest Products Laboratory, Madison, Wisconsin. The fungus was stored at room temperature on malt agar slants before use.

Radiochemicals. The following radiolabeled insecticides were a gift from J.R. Coats and L. Somasundaram, Iowa State Lniversity to S.N. Kakar: [2,6-phenyl-14C]chlorpyrifos, [Uring $-1+\mathrm{C}$ ]fonofos, and [methylene-1+C] terbufos. The trivial names of the three organophosphorous insecticides are used as a matter of convenience. The following names of these insecticides are recognized by the Chemical Abstracts Service (CAS): chlorpyrifos, phosphorothioic acid O,O-diethyl-O-(3,5,6-trichloro-2-pyridinyl) ester, fonofos, ethylphosphorodithioic acid O-ethyl-S-phenyl ester, terbufos, phosphorodithioic acid S-[[(1,1dimethylethyl)thio]methyl]-O-O-diethyl ester. The radiochemical purity of ${ }^{14} \mathrm{C}$-chlorpyrifos and ${ }^{14} \mathrm{C}$-fonofos was greater than $98 \%$, while the radiochemical purity of ${ }^{14} \mathrm{C}$-terbufos was $96 \%$. Structures of these compounds are presented in Figure 1. 
Experimental Conditions. Biodegradation studies were performed by using stationary cultures of $P$. chrysosporium grown in the nitrogen-limited medium described by Fenn and Kirk (11). Briefly, this medium consisted of $56 \mathrm{mM}$ glucose, $1.2 \mathrm{mM}$ ammonium tartrate, trace elements (12) and thiamine ( $1 \mathrm{mg} / \mathrm{L}$ ) in $20 \mathrm{mM}$ dimethylsuccinate (sodium) buffer, $\mathrm{pH} 4.2$ (11) Cultures received $1 \mathrm{~mL}$ of formaldehyde $[36 \%(\mathrm{w} / \mathrm{w})]$ to prevent microbial growth. All cultures were incubated at $37^{\circ} \mathrm{C}$.

Cultures $(10 \mathrm{~mL})$ were grown in sealed $250-\mathrm{mL}$ Wheaton bottles. The Teflon-lined cap of the bottles was modified by drilling two holes, into which a short and a long piece of glass tubing were inserted. The longer piece of glass tubing extended into the bottle to approximately $3 \mathrm{~cm}$ above the fungal mat. Epoxy glue was used to hold the tubing in place. These modified caps served as gas exchange manifolds. Wheaton bottles so modified have been used to demonstrate ${ }^{14} \mathrm{C}$-carbon dioxide evolution from ${ }^{14} \mathrm{C}$-labeled organopollutants in several studies (5-9). However, we have recently found that $500 \mathrm{~mL}$ Erlenmever flasks with ground-glass joints fitted with impingers (Ace Glass), originally designed for air sampling, can also be used for gas exchange. In experiments in which $500 \mathrm{~mL}$ Erlenmeyer flasks were used it was necessary to increase the volume of the cultures to $20 \mathrm{~mL}$ so that the fungal mat completely covered the bottom of the flask.

Radiolabeled compounds were added to cultures immediately after inoculation with fungal spores. Cultures were grown under ambient atmosphere during the first 3 days of incubation. On day 3 and at 3-day intervals thereafter, cultures were flushed with $\mathrm{O}_{2}$ for $20 \mathrm{~min}$ (Wheaton bottles) or $30 \mathrm{~min}$ (Erlenmeyer flasks), and the $\mathrm{CO}_{2}$ evolved was trapped in $10 \mathrm{~mL}$ of a solution containing ethanolamine-methanol-Safety Solve scintillation cocktail (Research Products International Corp., Mt. Prospect, Ilinois) (1:4:5). The amount of ${ }^{14} \mathrm{CO}_{2}$ trapped was determined by liquid scintillation spectrometry. Mass balance analyses were performed on cultures of $P$. chrysosporium that had been incubated with ${ }^{14} \mathrm{C}$-chlorpyrifos, ${ }^{14} \mathrm{C}$-fonofos, or ${ }^{14} \mathrm{C}$-terbufos for 18 or 21 days. 
Cultures (three or five replicates for each compound) were pooled and the individual culture flasks were rinsed with water $(40 \mathrm{~mL}$ total), which was added to the pooled cultures. The pooled cultures were then extracted three times with methylene chloride (100 mL total). Particulate material (mycelium) was separated from the aqueous fraction by filtration through glass wool. Samples of the particulate material and $1-\mathrm{mL}$ aliquots of the methylene chloride extracts and the aqueous fractions were placed in scintillation vials containing $10 \mathrm{~mL}$ of Safety Solve, and radioactivity was determined by liquid scintillation spectrometry.

For thin-layer chromatography (TLC), the solvent was removed from the methylene chloride extracts by evaporation under nitrogen. The residue was redissolved in a minimal amount of methylene chloride. TLC of ${ }^{14} \mathrm{C}$ chlorpyrifos (in hexane:acetone:glacial acetic acid [20:40:1]), ${ }^{14} \mathrm{C}$ fonofos (in chloroform:ethylacetate:hexane $[2: 2: 1]$ ), and ${ }^{14} \mathrm{C}$ terbufos (in nitromethane:acetonitrile:toluene [3:8:9]) was performed as recommended (J.R Coats and L.

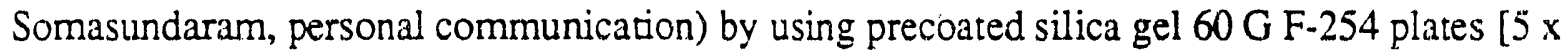
$20 \mathrm{~cm}$, (aluminum backed); thickness, $250 \mu \mathrm{m}$; E. Merck AG, Darmstadt, Germany]. After TLC, the elution solvents were evaporated under air. TLC plates were cut into $1-\mathrm{cm}$ strips, which were then moistened with water and placed in scintllation vials containing $20 \mathrm{~mL}$ of Safety Solve. With this procedure, the silica gel was desorbed from the aluminum backing and sertled on the bottom of the scintillation vial. Radioactivity was then deternined by liquid scintillation spectrometry.

\section{Results}

The ability of $P$. chrysosporium to degrade ${ }^{14} \mathrm{C}$ chlorpyrifos, ${ }^{14} \mathrm{C}$ fonofos, and ${ }^{14} \mathrm{C}$ terbufos is illustrated in Table 1 and Figures 2-7. In all cases, substantial amounts $(27.5 \%$, $12.2 \%$, and $26.6 \%$, respectively) of chlorpyrifos, fonofos, and terbufos were degraded to ${ }^{14} \mathrm{CO}_{2}$ during the 18-day incubation in nitrogen-limited stationary cultures of this fungus. Only the 
aromaric ring carbons of chlorpyrifos and fonofos were labeled. Thus, these results demonstrate that the chlorinated pyridinyl ring of chlorpyrifos and the phenyl ring of fonofos undergo ring cleavage during biodegradation by $P$. chrysosporium.

Degradation was also assessed by mass balance analysis. After incubation, cultures were extracted with methylene chloride. Results (Table 1) show that considerable amounts of all of these compounds were converted to metabolites that partitioned into the aqueous phase. Similarly, TLC revealed the presence of several metabolites of these compounds in the methylene chloride fractions (Figures 5-7). Considerable nonbiological degradation occurred in controls as evidenced by metabolite formation in sterile culture medium (data not shown). Controls also suggested that chlorpyrifos, fonofos, and terbufos might be susceptible to air stripping and that volatilization might account for the low mass recovery observed in several experiments and controls.

Because of the low mass recoveries, additional experiments (Table 2) were performed in which cultures $(20 \mathrm{~mL})$ were incubated in $500-\mathrm{mL}$ Erlenmeyer flasks with ground-glass joints fitted with a glass impinger for gas exchange. A trap for volatile organics was placed immediately before the carbon dioxide trap. The latex tubing used in this apparatus was assayed for absorbed radioactivity. Results were similar to those reported in Table 1 and are consistent with the conclusion that substantial amounts of all of these pesticides are degraded by $P$. chrysosporium. In general, mass recoveries were improved by using these procedures. However. although some radiolabeled material was retained by the volatile traps and some was absorbed by the latex tubing, we were still unable to account for substantial amounts of mass in some experiments. We suggest that most of this mass may have been lost during manipulations involved with the methylene chloride extraction. In control experiments, the amount of ${ }^{14} \mathrm{C}$-labeled material found in ${ }^{14} \mathrm{CO}_{2}$ traps was never greater than $1.0 \%$ of the radioactivity initially present, demonstrating that ${ }^{14} \mathrm{CO}_{2}$ formation was not a major factor in the nonbiological disappearance observed. 


\section{Discussion}

Organophosphorus insecticides are useful because they are relatively inexpensive, fairly simple to manufacture, and effective against a wide variety of insect pests $(1,2)$. As a group, they are relatively quickly degraded in the environment $(1,2)$. A number of organophosphorous insecticides do, however, have half-lives on the order of several months and may be thought of as moderately persistent. For example, in a nonsterile Sultan silt loam soil incubated with $50 \mathrm{nM}$ of ${ }^{14} \mathrm{C}$-chlorpyrifos for 8 months, $26.1 \%$ of the radioactivity was recovered as undegraded ${ }^{14} \mathrm{C}$ chlorpyrifos, $33 \%$ was recovered as ${ }^{14} \mathrm{C}$-3,5,6-trichloro-2-pyridinol, 33\% was not extractable from the soil; $1.1 \%$ was converted to unidentified water-soluble metabolites, and $6.6 \%$ was degraded to ${ }^{14} \mathrm{CO}_{2}$ (3). In other words, more than $92 \%$ of the ${ }^{14} \mathrm{C}$-chlorpyrifos originally present remained undegraded, as a biologically active metabolite, or in a form that was tightly bound to soil after 8 months of incubation.

The biodegradation of organophosphorous insecticides has been studied in soils and in bacterial cultures $(1-4)$. Less attention has been given to the biodegradation of these compounds by fungi. Fenitrothion [phosphorothioic acid O,O-dimethyl-O-(3-methyl-4-nitrophenyl) ester] is, however, known to be degraded by Trichoderma viride, Mortierella isabellina, and Saprolegnia parasitica (13). The present study showed that $P$. chrysosporium degraded chlorpyrifos, fonofos, and terbufos to carbon dioxide. Trichodrma viride, $M$. isabellina, and $P$. chrysosporium are all members of the Deuteromycotina, the Zygomycotina, and the Basidiomycotina, respectively, in the division Amastigomycota, whereas S. parasitica is a member of the division Mastigomycota. These limited results suggest that the ability to degrade organophosphorous insecticides may be widespread or at least relatively common among the fungi.

Compared to truly persistent environmental pollutants such as DDT, dieldrin, and chlordane, organophosphorous insecticides in most soils do not present bioremediation problems. 
Exceptions might exist in cases of inadvertent overapplication or repeated application and in accumulation in soils containing inordinately low levels of microbial activity. In these cases it would be logical to amend the soils with microorganisms having the documented ability to degrade the organophosphorous compound in question. If $P$. chrysosporium were used, a suitable, inexpensive growth substrate would also likely be required, because this fungus typically does not use xenobiotics as growth substrates. Growth of $P$. chrysosporium and degradation of environmentally persistent organopollutants in soils has been demonstrated by using several inexpensive plant residues including ground corn cobs, wood chips, peat, and wheat straw $(14,15)$.

The ability of lignin-degrading fungi such as $P$. chrysosporium to degrade organophosphorous insecticides may be important from another perspective. Pesticide residues or their metabolites are often incorporated into the insoluble fraction of plants and soils. Some of this insoluble material is undoubtedly lignin or lignin-derived material. Such immobilization represents a form of pesticide inactivation and is sometimes a goal of bioremediation efforts. The immobilized material must eventually undergo turnover and further degradation. Indeed, proponents of immobilization techniques emphasize that release of bound pollutants is expected to occur slowly and at levels that are environmentally insignificant (16). Phanerochaete chrysosporium can degrade chlorinated anilines covalently incorporated into lignin (10). Thus, in soils, lignin-degrading fungi might accelerate degradation of organopollutants that are covalently bound to lignin or lignin-derived material. This technology is promising, but the mictobial ecology and biodegradative ability of lignin-degrading fungi in soil require further scrutiny. 


\section{Acknowledgments}

This research was supported by a Cooperative Research and Development Agreement between the U.S. Department of Energy (Argonne National Laboratory) under CRADA Agreement 73368 with the University of Notre Dame.

\section{References}

1. Matsumura, F., Toxicology of Insecticides, 1985 Second edition, Plenum Press, New York.

2. Chambers,J.E., Levi, P.E., Organophosphates: Chemistry, Fate and Effects, 1992 Academic Press, New York.

3. Getzin, L.W., "Degradation of Chlorpyrifos in Soil: Influence of Autoclaving, Soil Moisture, and Temperature," J. Econ. Entomol. 1981, 71, 158-162.

4. Racke, K.D., Coats, J.R., "Comparative Degradation of Organophosphorous Insecticides in Soil: Specificity of Enhanced Microbial Degradation," J. Agric. Food Chem. 1988, 36, 193 199.

5. Bumpus, J.S., Tien, M., Wright, D., Aust, S.D., "Oxidation of Persistent Environmental Pollutants by a White Rot Fungus." Science 1985, 228, 1434-1436.

6. Bumpus, J.A., Aust, S.D., "Biodegradation of Environmental Pollutants by the White Rot Fungus Phanerochaete chrysosporium: Involvement of the Lignin Degrading System." BioEssays 1987, 6, 166-170. 
7. Bumpus, J.A., Aust, S.D., "Biodegradation of DDT [1,1,1-Trichloro-2,2-bis-(4chlorophenyl)ethane] by the White Rot Fungus Phanerochaete chrysosporium," Appl. Environ. Microbiol. 1987, 53, 2001-2008.

8. Mileski, G.J., Bumpus, J.A., Jurek, M.A., Aust, S.D., "Biodegradation of Pentachlorophenol by the White Rot Fungus Phanerochaete chrysosporium," Appl. Environ. Microbiol. 1988, 54, 2885-2889.

9. Fernando, T., Bumpus, J.A., Aust, S.D., "Biodegradation of TNT (2,4,6-Trinitrotoluene) by Phanerochaete chrysosporium," Appl. Environ. Microbiol. 1990, 56, 1666-1671.

10. Arjmand, M., Sandermann, Jr., H., Mineralization of Chloroaniline/Lignin Conjugates and of Free Chloroanilines by the White Rot Fungus Phanerochaete chrysosporium," J. Agric. Food Chem. 1985, 33, 1055-1060.

11. Fenn, P., Kirk, T.K., "Ligninolytic System of Phanerochaete chrysosporium: Inhibition by o-Phthalate," Arch. Microbiol. 1979, 123, 307-309.

12. Kirk, T.K., Schultz, E., Connors, W.J., Lorenz, L.F., Zeikus, J.G., "Influence of Culture Parameters on Lignin Metabolism by Phanerochaete chrysosporium," 1977, Arch. Microbiol. 177, 277-285.

13. Baarschers, W.H., Heitland, H.S., "Biodegradation of Fenitrothion and Fenitrooxon by the Fungus Trichoderma viride," J. Agric. Food Chem. 1986, 34, 707-709. 
14. Fernando, T., Aust, S.D., Bumpus, J.A., "Effects of Culture Parameters on DDT [1,1,1Trichloro-2,2-bis (4-Chlorophenyl) ethane\} Biodegradation by Phanerochaete chrysosporium," Chemosphere 1989, 19, 1387-1398.

15. Lamar, R.T., Dierrich, D.M., "In Situ Depletion of Pentachlorophenol from Contaminated Soil by Phanerochaete spp," Appl. Environ. Microbiol. 1990, 56, 3090-3.100.

16. Dec, J., Bollag, J.M., "Microbial Release and Degradation of Catechol and Chlorophenols Bound to Synthetic Humic Acid," Soil Sci. Soc. Am. J. 1988, 52, 1366-1371. 


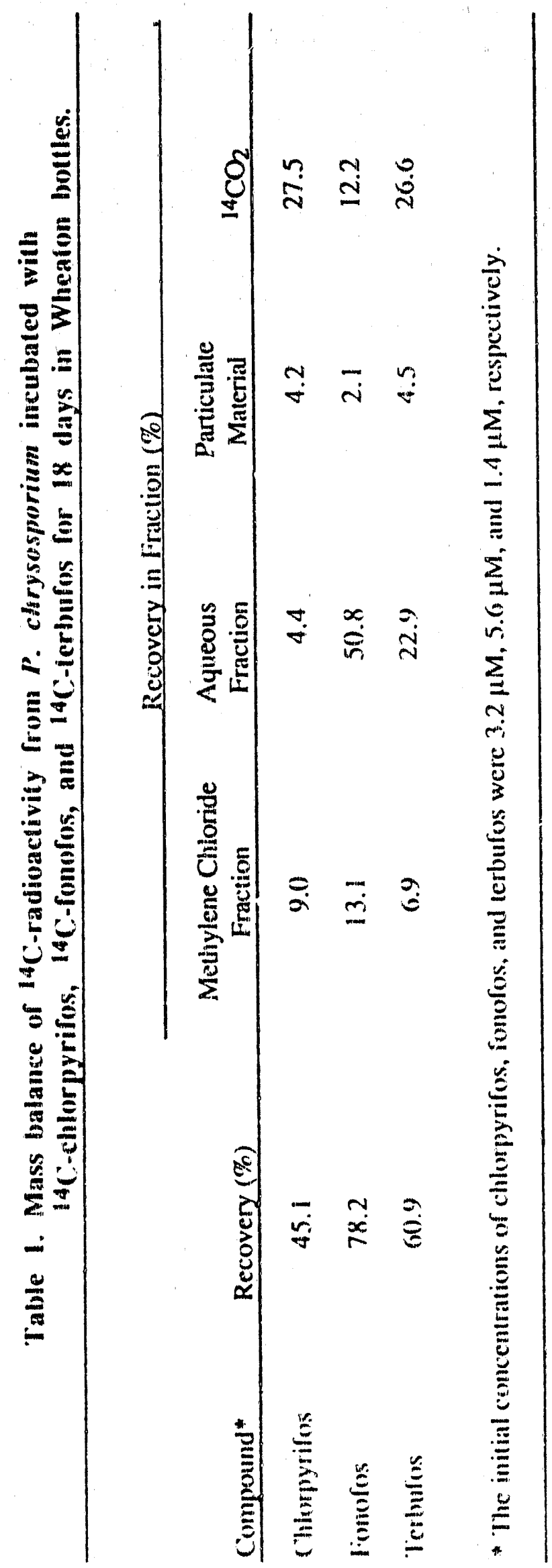




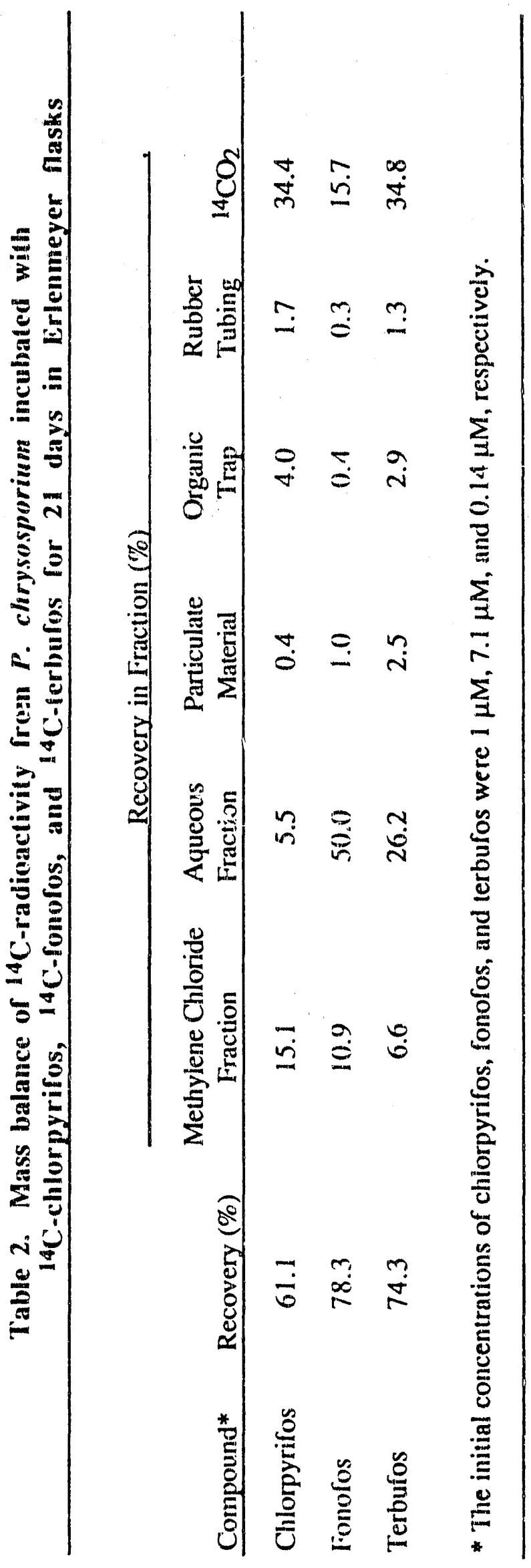




\section{Figure legends}

Figure 1. Structures of organophosphorous insecticides used in this investigation.

Figure 2. Mineralization of ${ }^{14} \mathrm{C}$-chlorpyrifos by $P$. chrysosporium. The initial concentration of ${ }^{14} \mathrm{C}$ chlorpyrifos was $3.2 \mu \mathrm{M}$. Each point (open squares) represents the mean of five determinations \pm the standard deviation. An ininoculated culture served as the control (closed triangles).

Figure 3. Mineralization of ${ }^{14} \mathrm{C}$-fonofos by $P$. chrysosporium. The initial concentration of ${ }^{14} \mathrm{C}$ fonofos was $5.6 \mu \mathrm{M}$. Each point (open squares) represents the mean of five Neterminations \pm the standard deviation. An ininoculated culture served as the control (closed triangles).

Figure 4. Mineralization of ${ }^{14} \mathrm{C}$-terbufos by $P$. chrysosporium. The initial concenuzation of ${ }^{14} \mathrm{C}$ terbufos was $1.4 \mu \mathrm{M}$. Each point (open squares) represents the mean of five determinations \pm the standard deviation. An ininoculated culture served as the control (closed triangles).

Figure 5. TLC of ${ }^{14} \mathrm{C}$-chlorpyrifos before incubation (top) and ${ }^{14} \mathrm{C}$ in methylene chloride extract of cultures of $P$. chrysosporium incubated with ${ }^{14} \mathrm{C}$-chlorpyrifos for 18 days (bottom).

Figure 6. TLC of ${ }^{14} \mathrm{C}$-fonofos before incubation (top) and ${ }^{14} \mathrm{C}$ in methylene chloride extract of cultures of $P$. chrysosporium incubated with ${ }^{14} \mathrm{C}$-fonofos for 18 days (bottom).

Figure 7. TLC of ${ }^{14} \mathrm{C}$-terbufos before incubation (top) and ${ }^{14} \mathrm{C}$ in methylene chloride extract of cultures of $P$. chrysosporium incubated with ${ }^{14} \mathrm{C}$ terbufos for 18 days (bottom). 


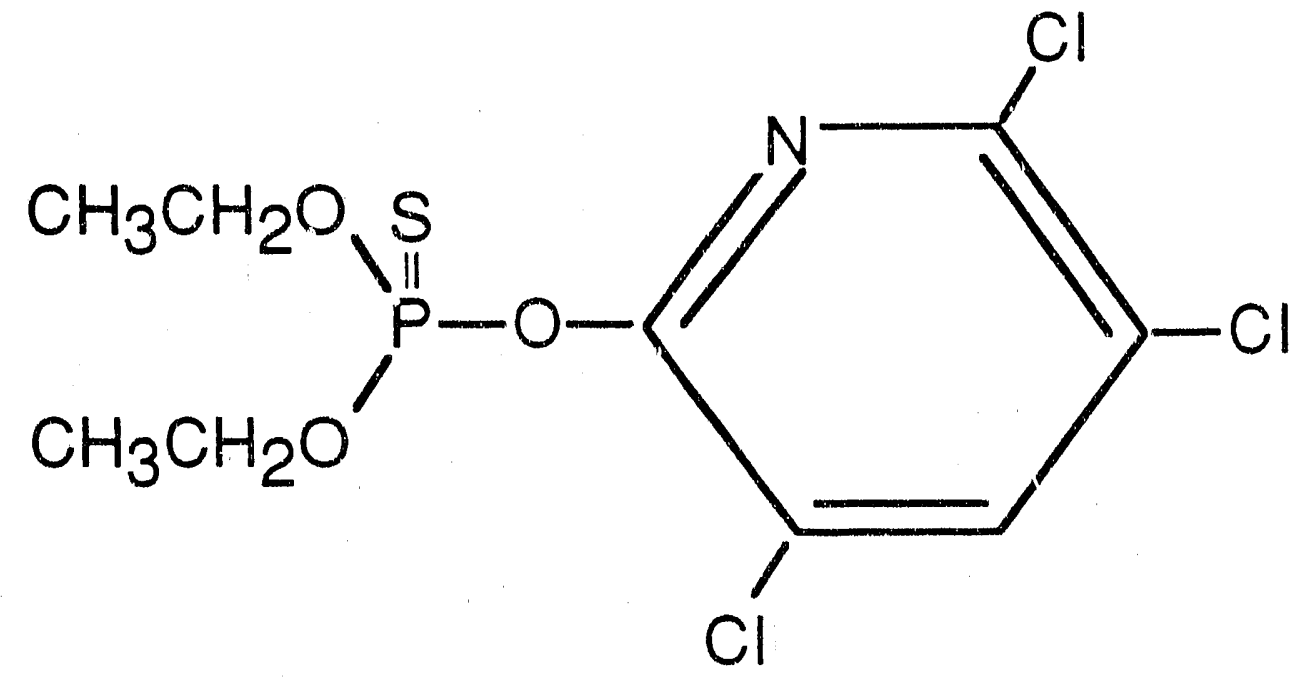

Chlorpyrifos

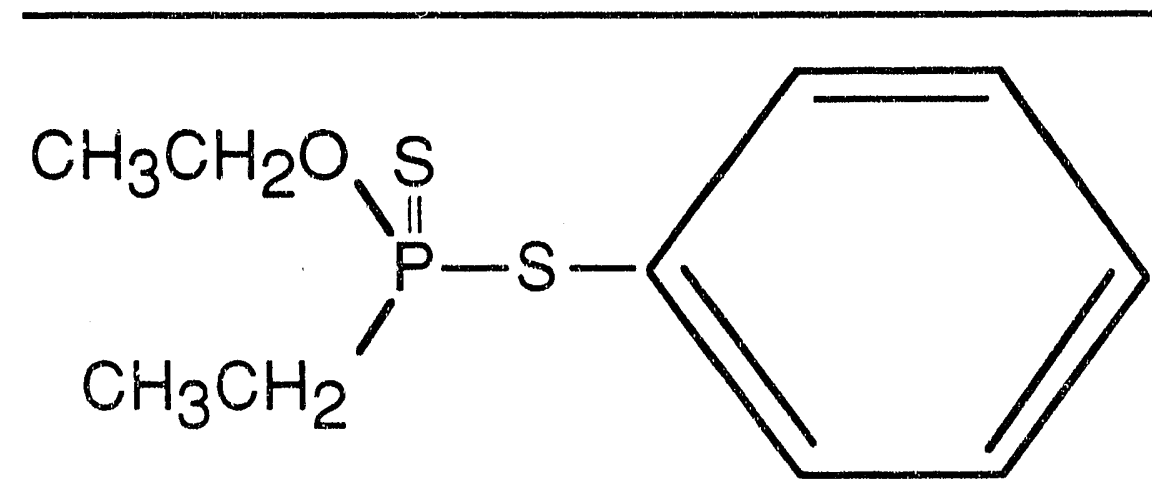

Fonofos

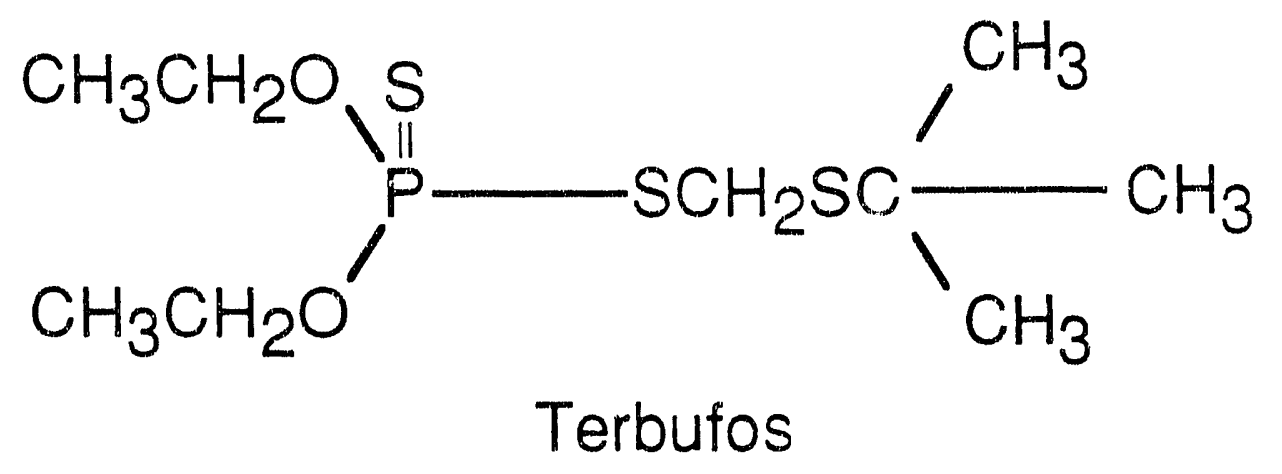




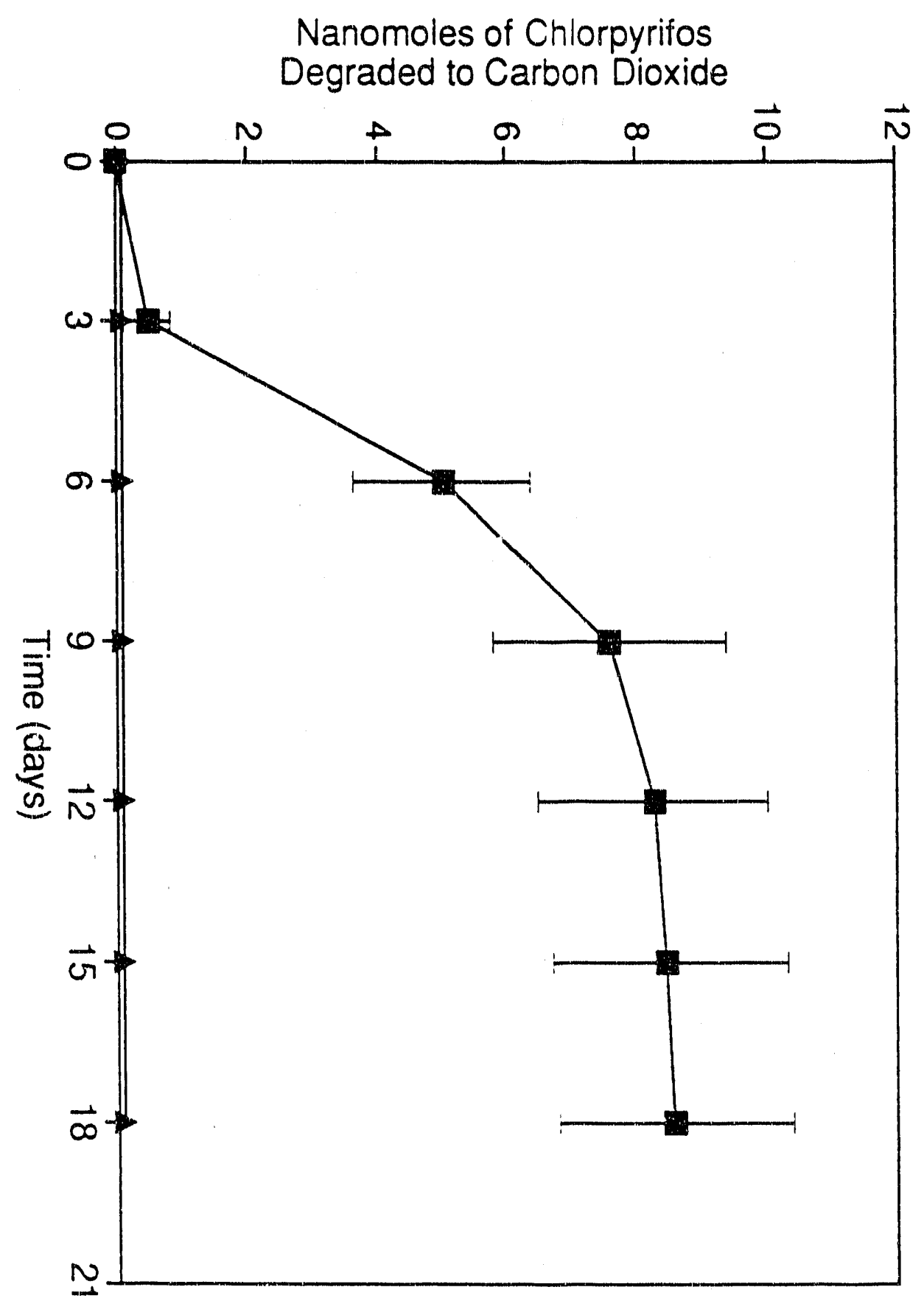




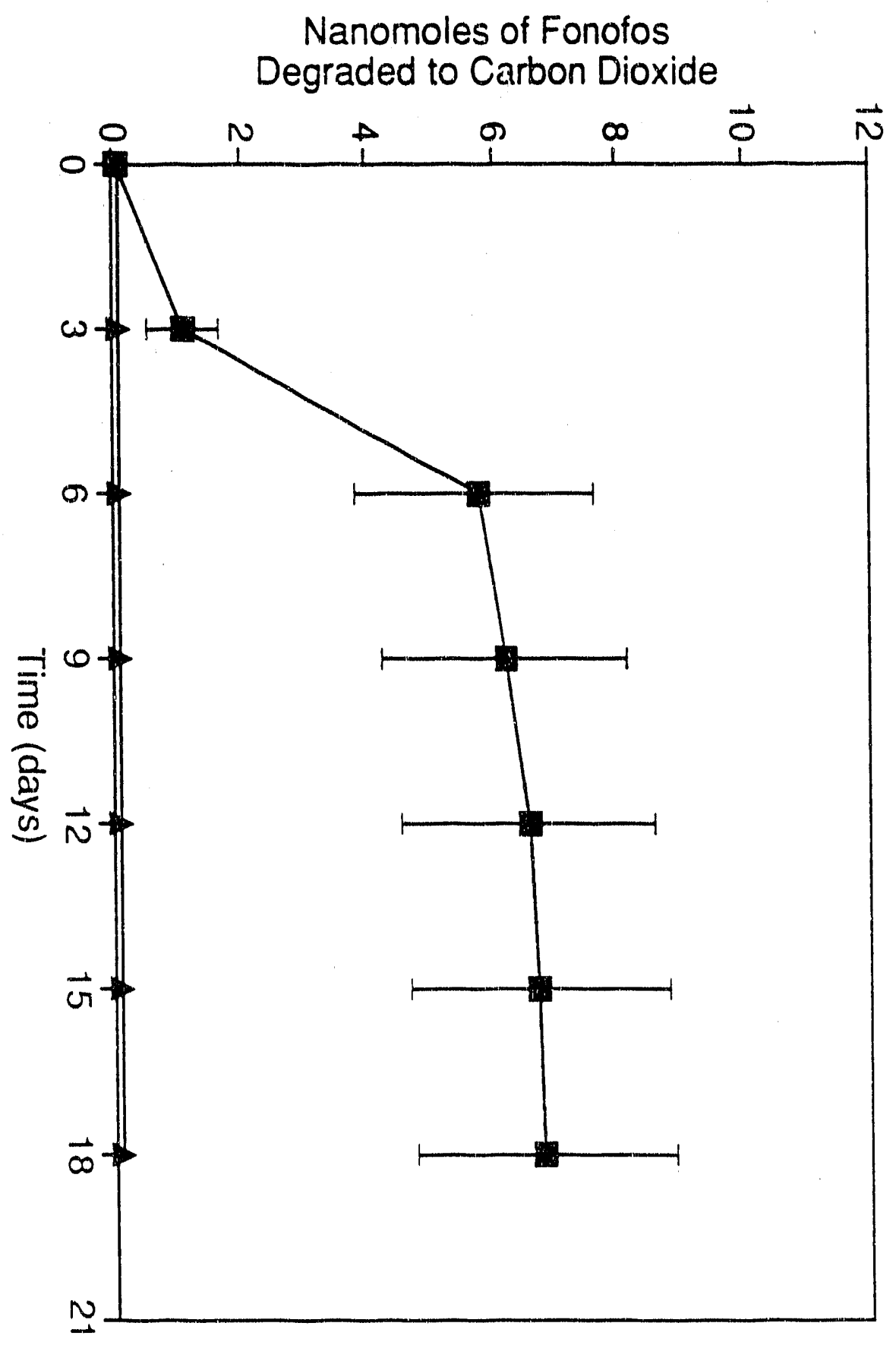




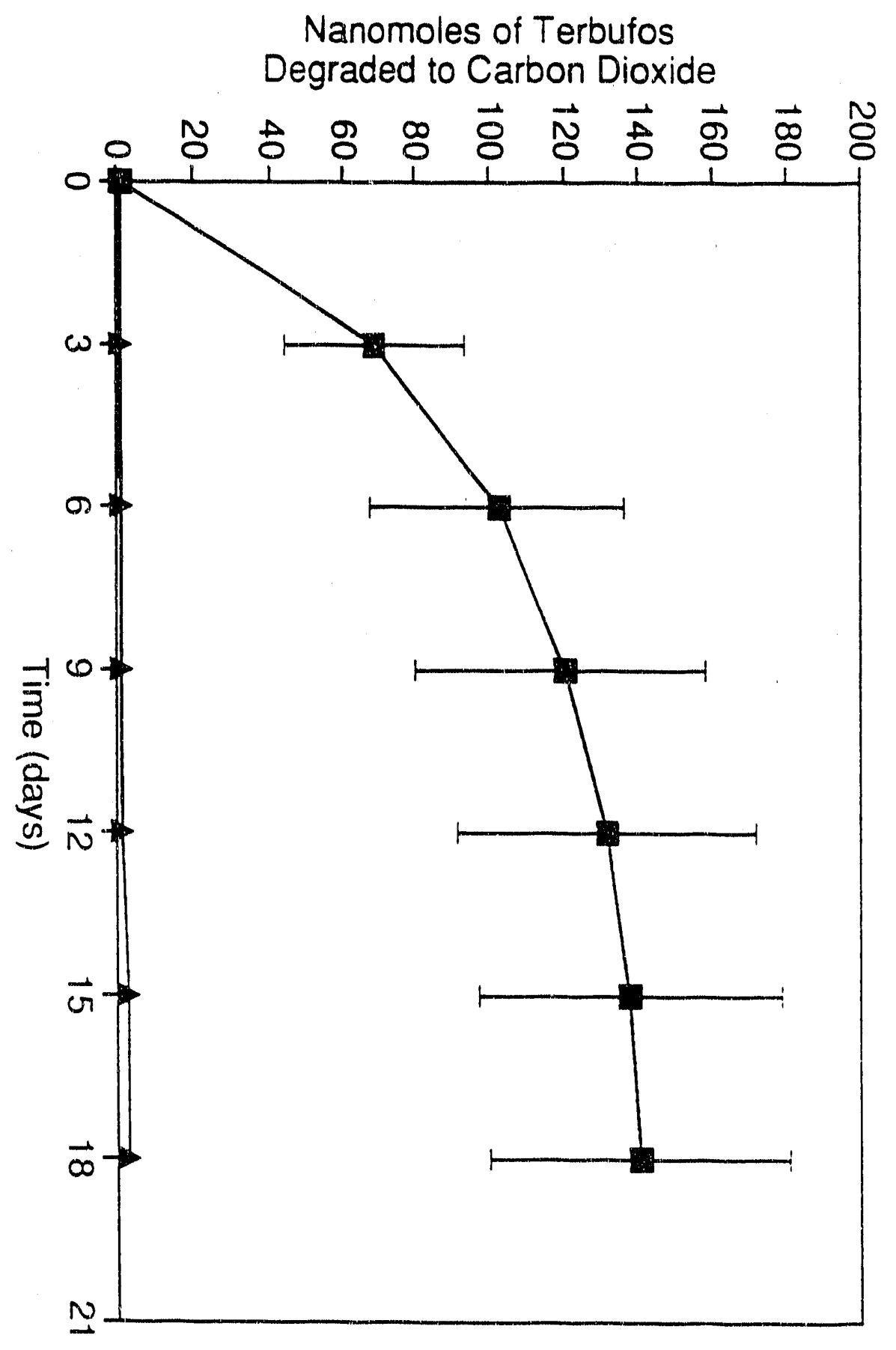



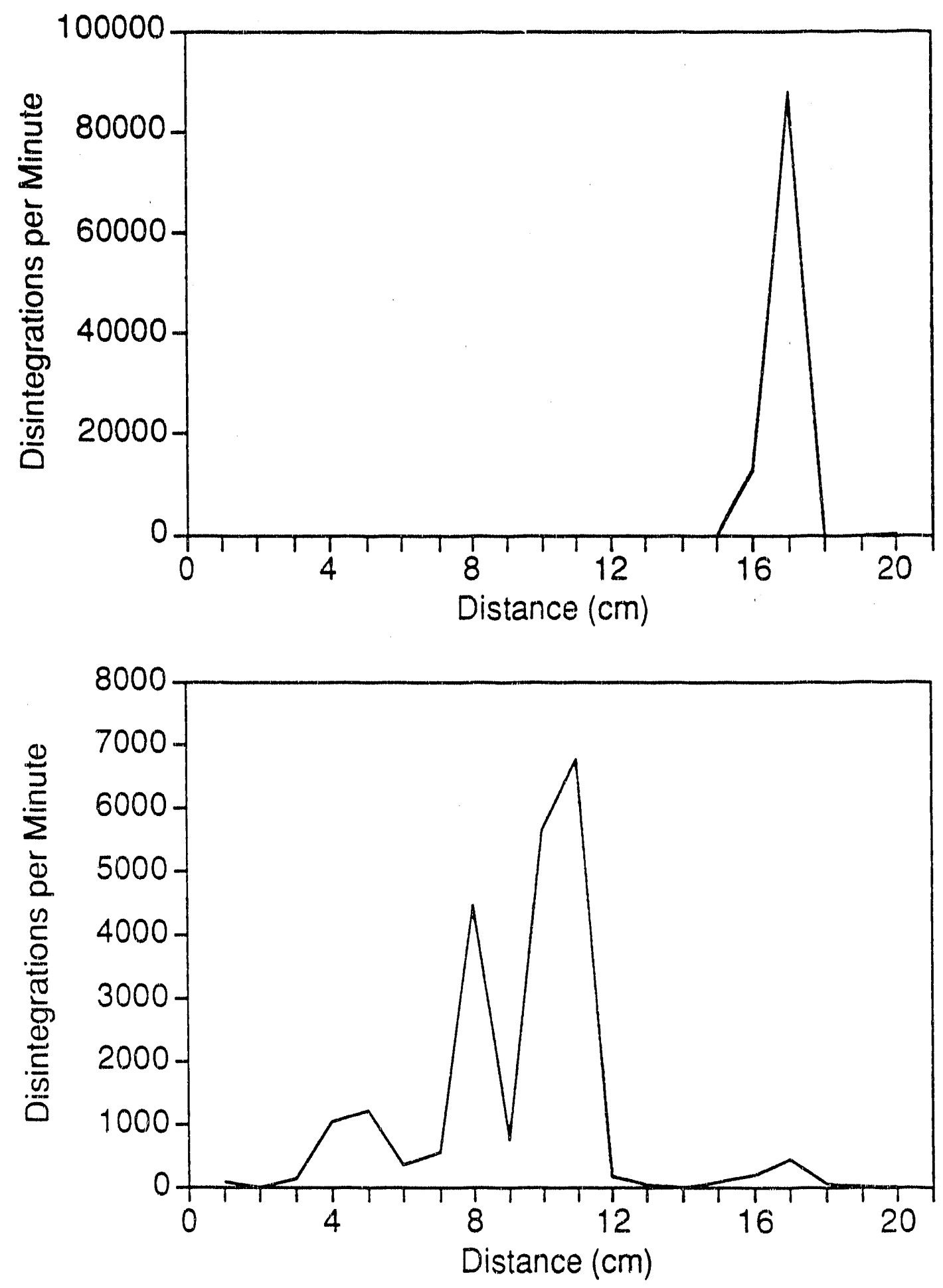

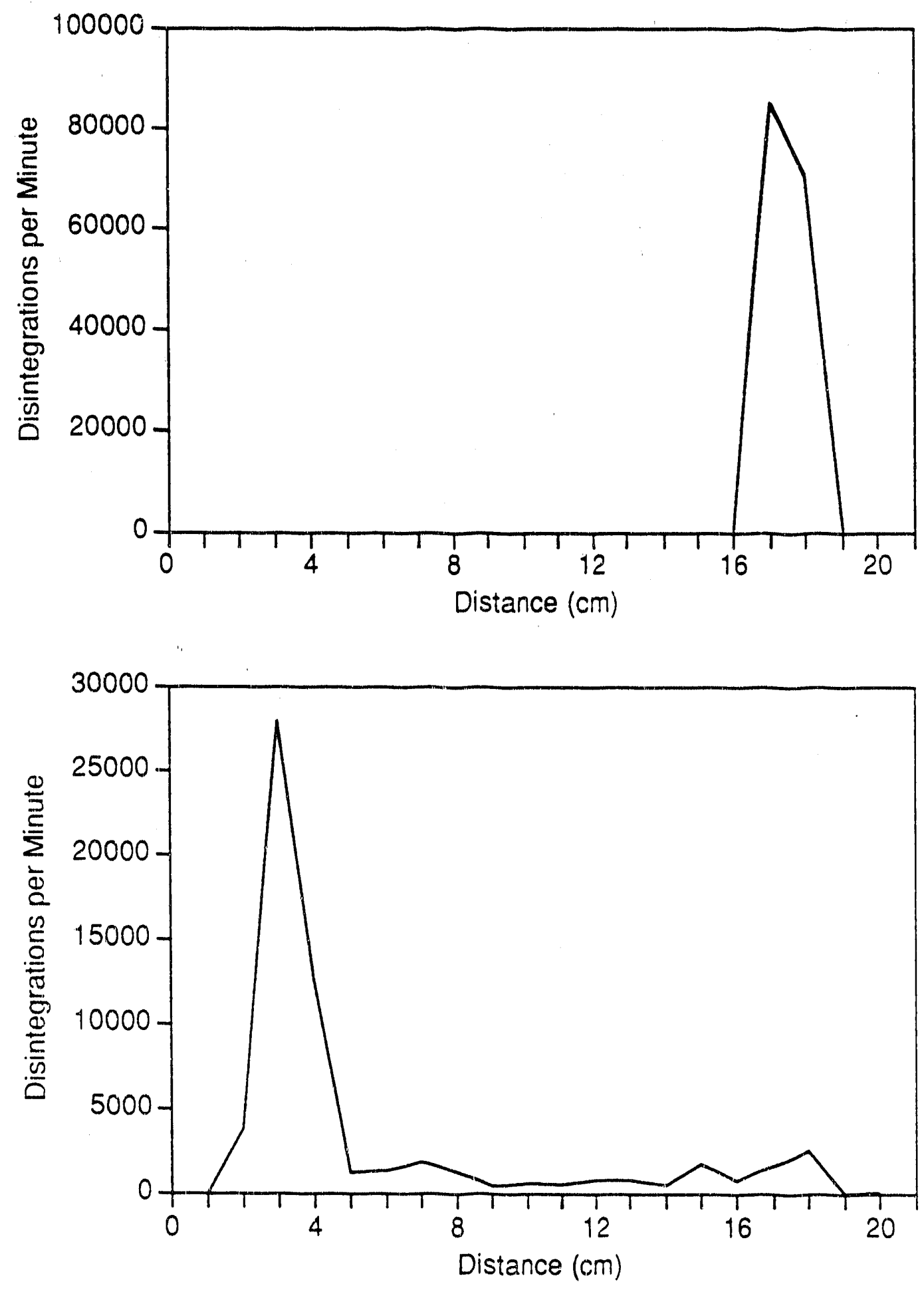

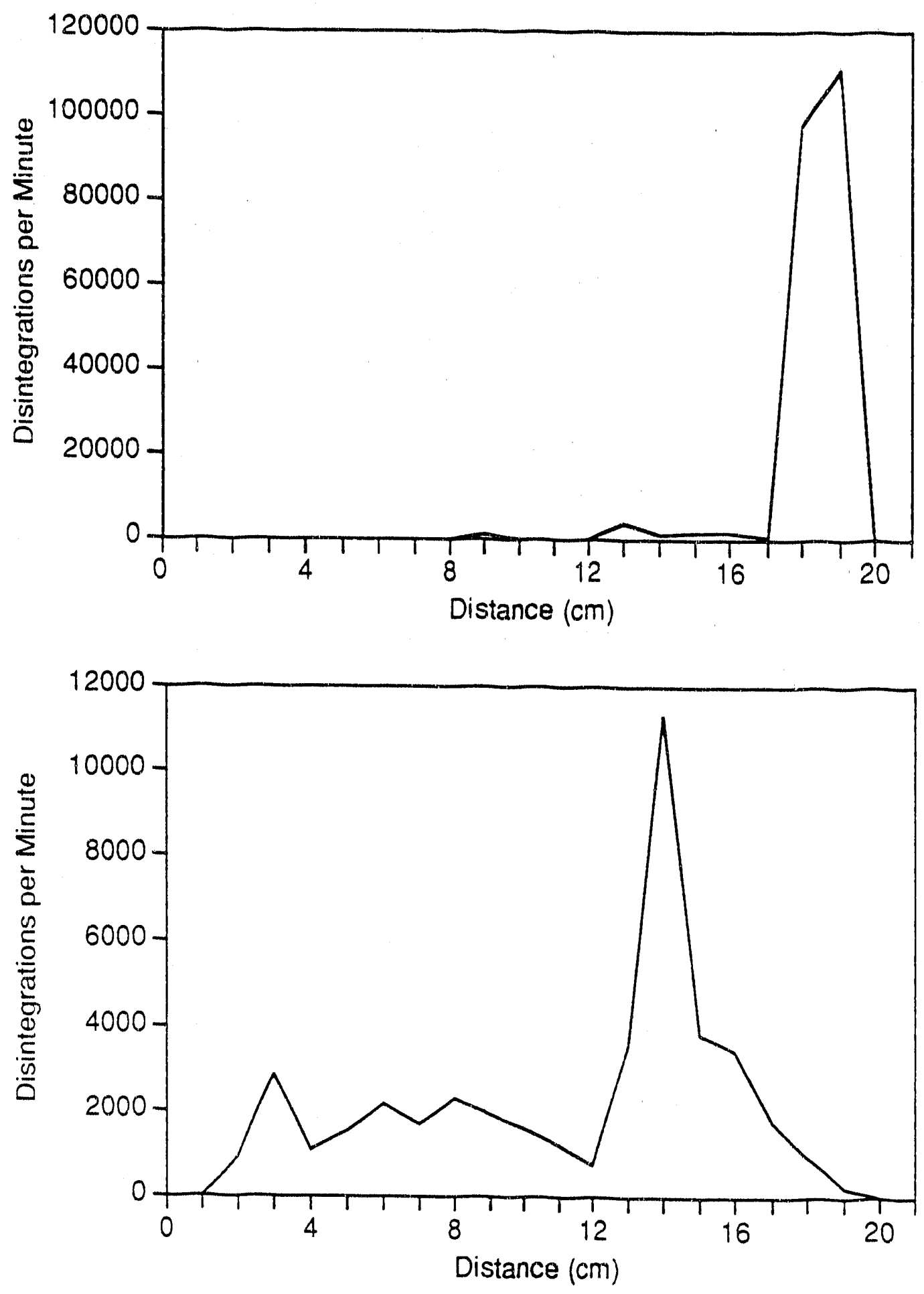

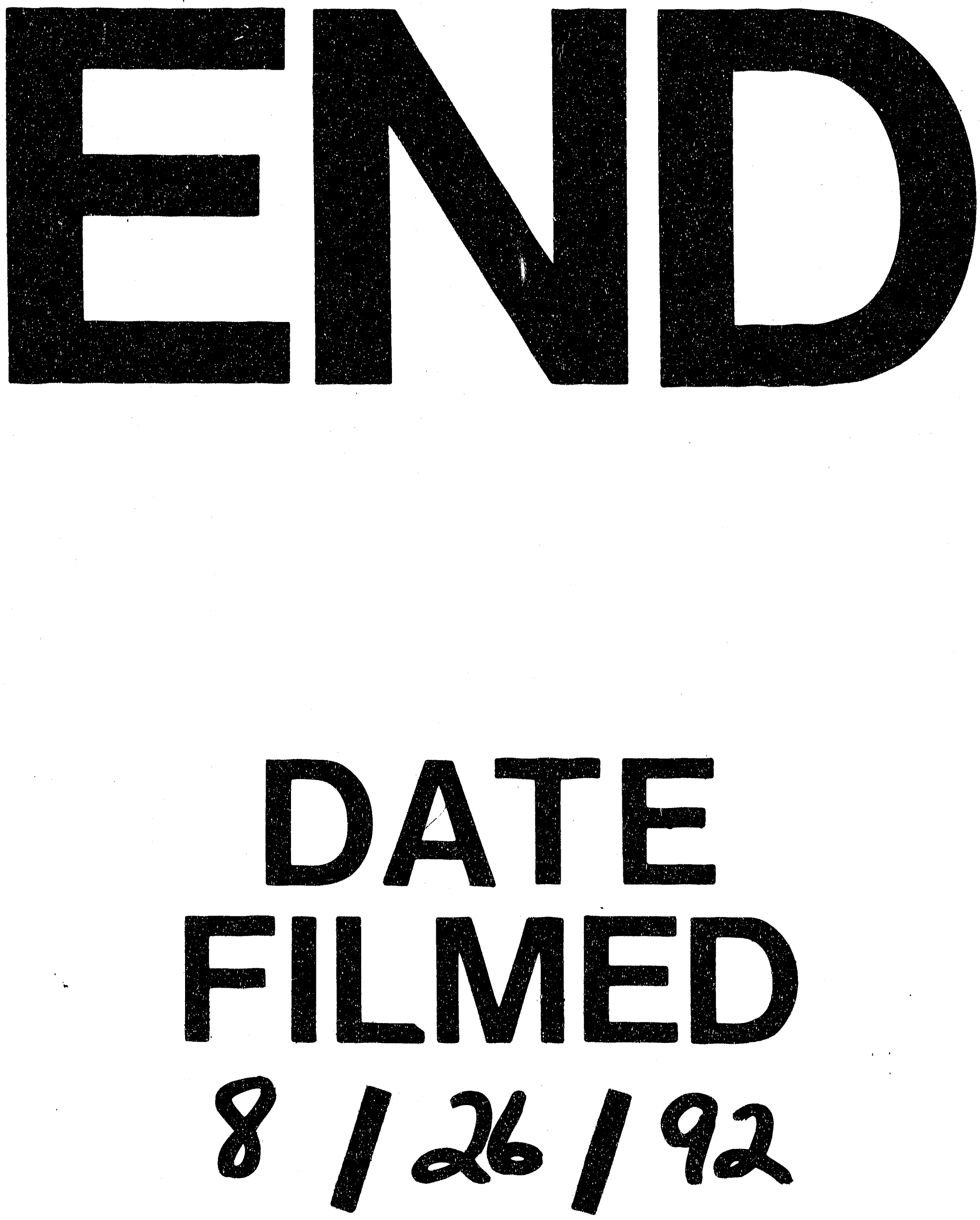
